\title{
Bile duct ligation increased dopamine levels in the cerebral cortex of rats partly due to induction of tyrosine hydroxylase
}

\author{
Weimin kong ${ }^{1}$, Xueying Sun ${ }^{1}$, Siyu $\mathrm{Yu}^{1}$, Peihua Liu ${ }^{1}$, Xiaoke zheng ${ }^{1}$, Jiaxin Zhang ${ }^{1}$, Liang \\ $\mathrm{Zhu}^{1}$, Tianxin Jiang${ }^{1}$, Mengmeng $\mathrm{Jin}^{1}$, Jinghui Gao ${ }^{1}$, XiaoDong Liu ${ }^{1}$, and Li Liu ${ }^{1}$ \\ ${ }^{1}$ China Pharmaceutical University
}

March 13, 2021

\begin{abstract}
Background and Purpose Liver failure is often associated with psychiatric alterations, partly resulting from the increased dopamine levels in brain. We aimed to investigate relationship between increased dopamine levels and mental abnormalities using bile duct ligation (BDL) rats and document mechanism that liver failure increased dopamine levels in SH-SY5Y cells. Experimental Approach Psychiatric alterations were operated following 14-day BDL. Dopamine and its metabolite levels in cortex, expressions of enzymes and transporters related to dopamine metabolism and transport in cortex and hippocampus were measured. SH-SY5Y cells were used to investigate whether $\mathrm{NH} 4 \mathrm{Cl}$, bile acids and bilirubin affected expression of tyrosine hydroxylase $(\mathrm{TH})$ or not. TH expression in SH-SY5Y cells co-incubated with bilirubin and signal pathway inhibitors was measured. Key Results Open-field test results showed a remarkable increase in exploratory behavior following BDL. BDL increased dopamine levels and expression of TH protein in cortex. MAO-A and Mb-COMT slightly but significantly decreased. Data from SH-SY5Y cells showed that increased bilirubin levels was a factor in inducing TH expression. Both inhibitor of $\mathrm{NF}-\varkappa \mathrm{B}$ pathway BAY117082 and silencing p65 remarkably reversed bilirubin-induced upregulation of $\mathrm{TH}$ protein. NF- $\varkappa \mathrm{B}$ activator TNF- $\alpha$ increased expression of TH protein. Roles of bilirubin in TH expression and increases in dopamine levels were documented using hyperbilirubinemia rats. Significant increases in dopamine levels, expressions of TH, p65 and p-p65 protein were observed in hyperbilirubinemia rats. Conclusion and Implications BDL significantly increased dopamine levels in rat cortex partly due to bilirubin-mediated TH induction. Increased bilirubin induced TH expression via activating $\mathrm{NF}-\varkappa \mathrm{B}$ signaling pathway.
\end{abstract}

\section{Hosted file}

Manuscripts.pdf available at https://authorea.com/users/401396/articles/513485-bileduct-ligation-increased-dopamine-levels-in-the-cerebral-cortex-of-rats-partly-due-toinduction-of-tyrosine-hydroxylase

\section{Hosted file}

Table 1.pdf available at https://authorea.com/users/401396/articles/513485-bile-ductligation-increased-dopamine-levels-in-the-cerebral-cortex-of-rats-partly-due-toinduction-of-tyrosine-hydroxylase

\section{Hosted file}

Table 2.pdf available at https://authorea.com/users/401396/articles/513485-bile-ductligation-increased-dopamine-levels-in-the-cerebral-cortex-of-rats-partly-due-toinduction-of-tyrosine-hydroxylase

\section{Hosted file}


Table 3.pdf available at https://authorea.com/users/401396/articles/513485-bile-ductligation-increased-dopamine-levels-in-the-cerebral-cortex-of-rats-partly-due-toinduction-of-tyrosine-hydroxylase

A
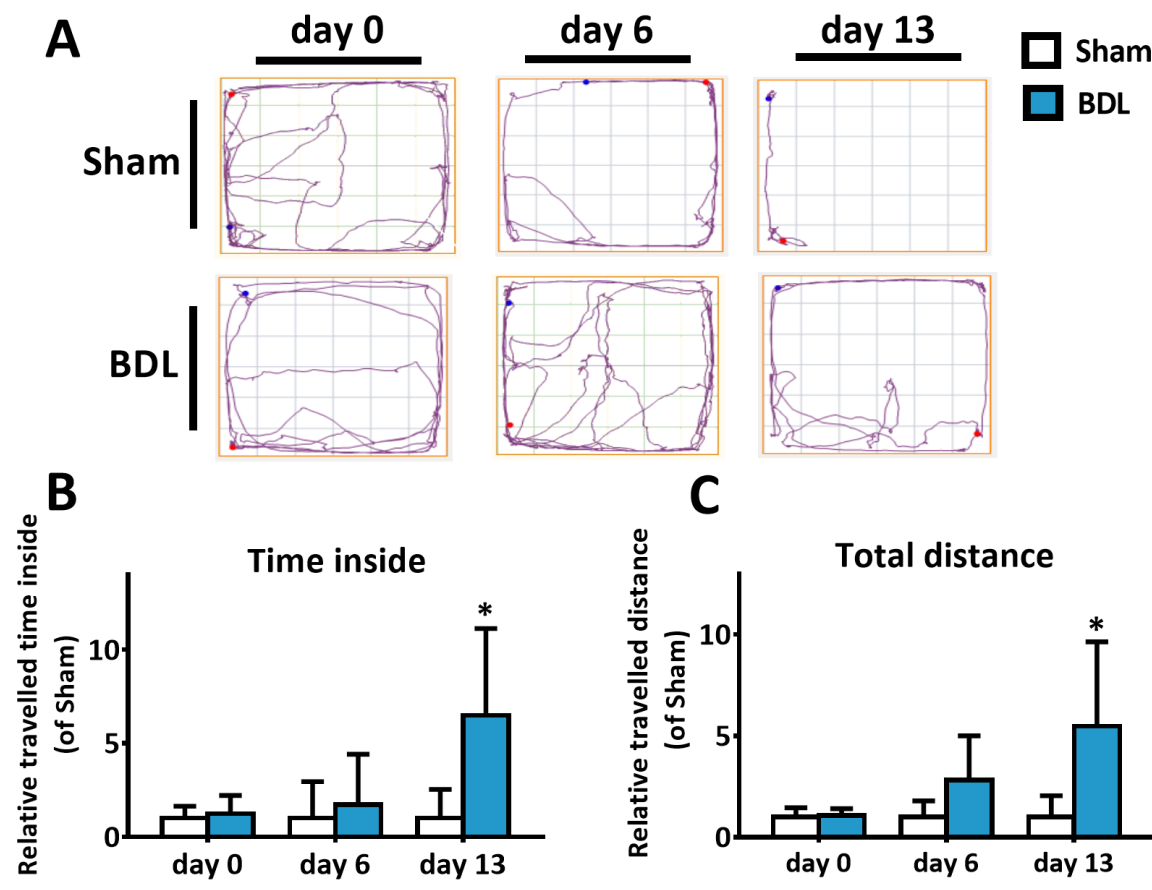

\section{C}
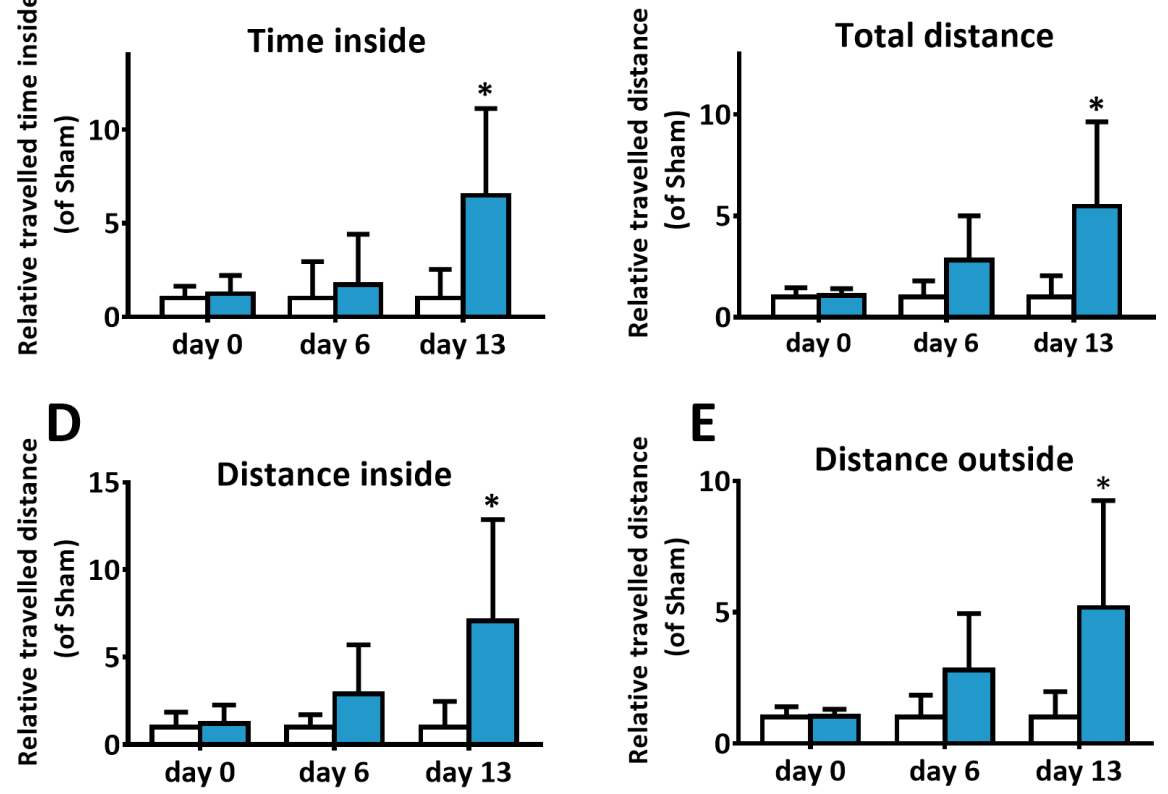

Figure 1 

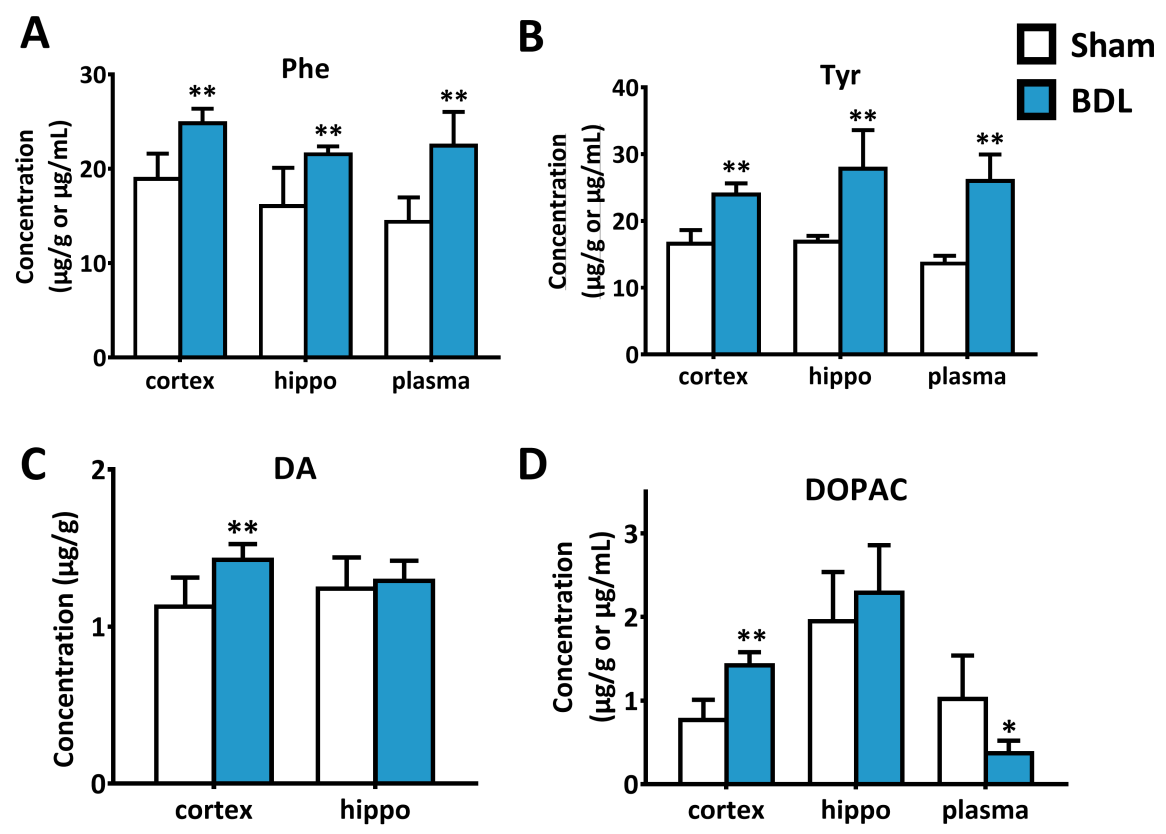

Figure 2
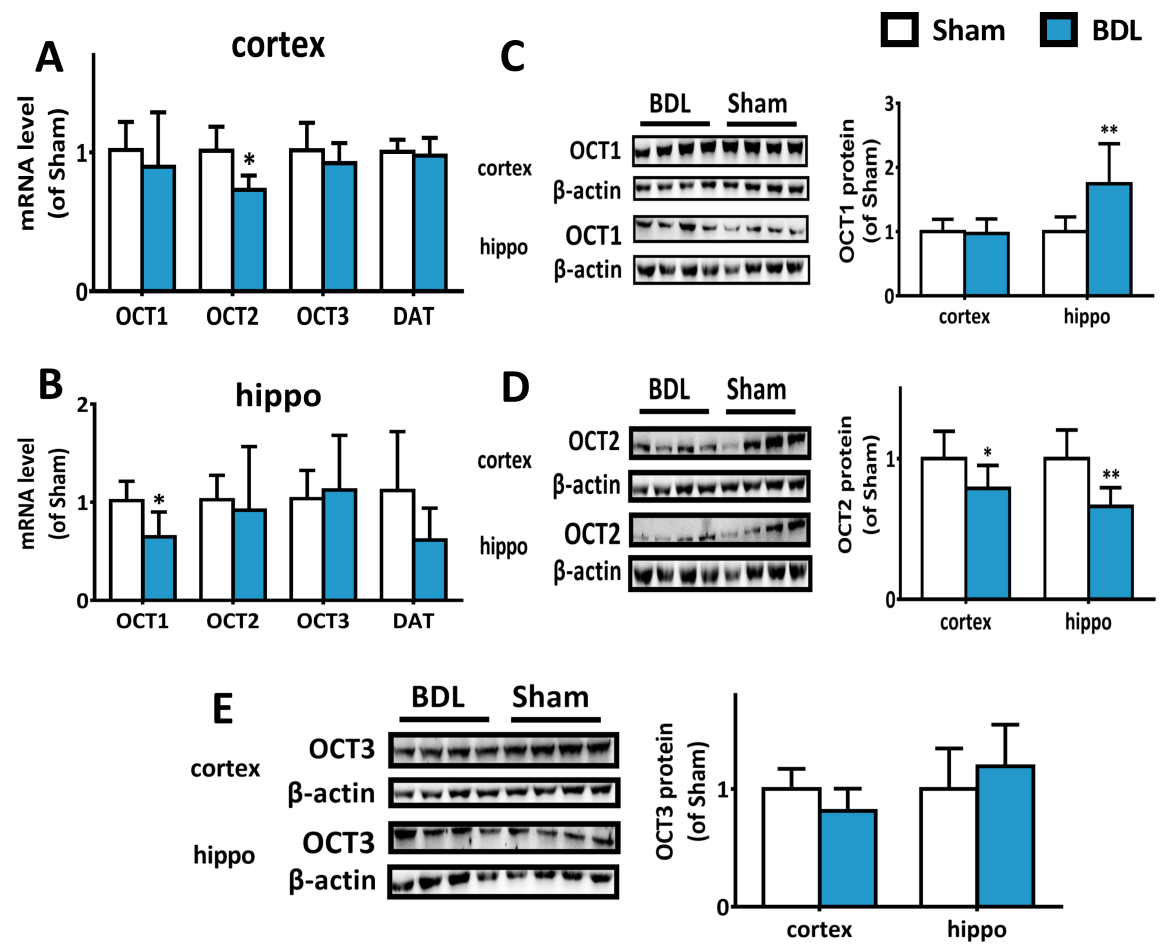

Figure 3 

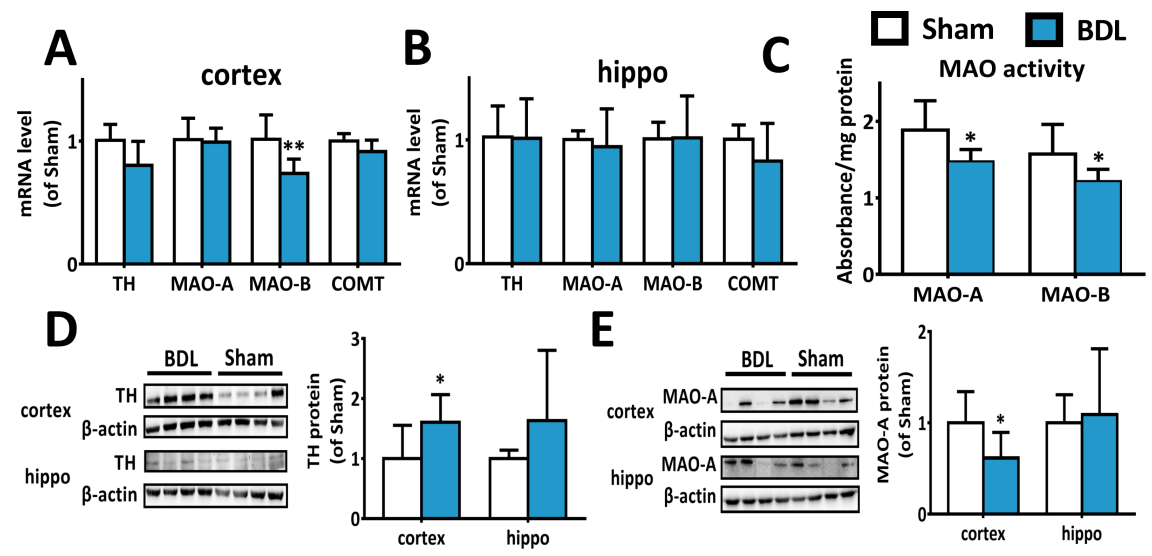

E
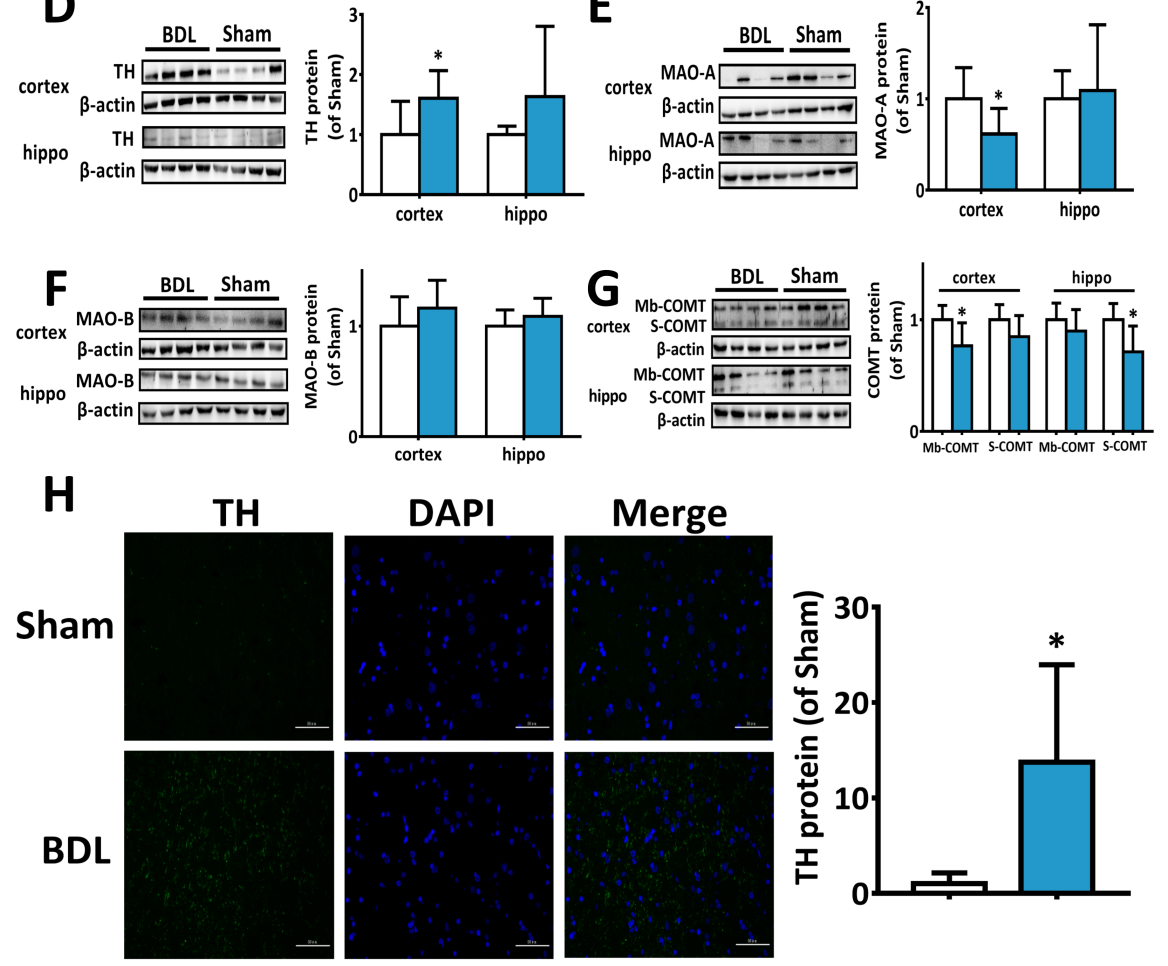

Figure 4 

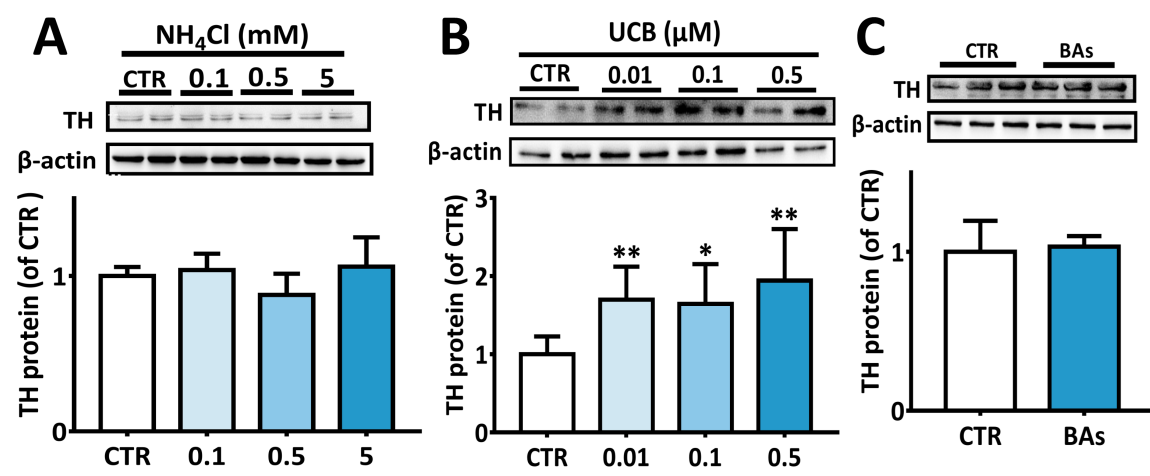

D
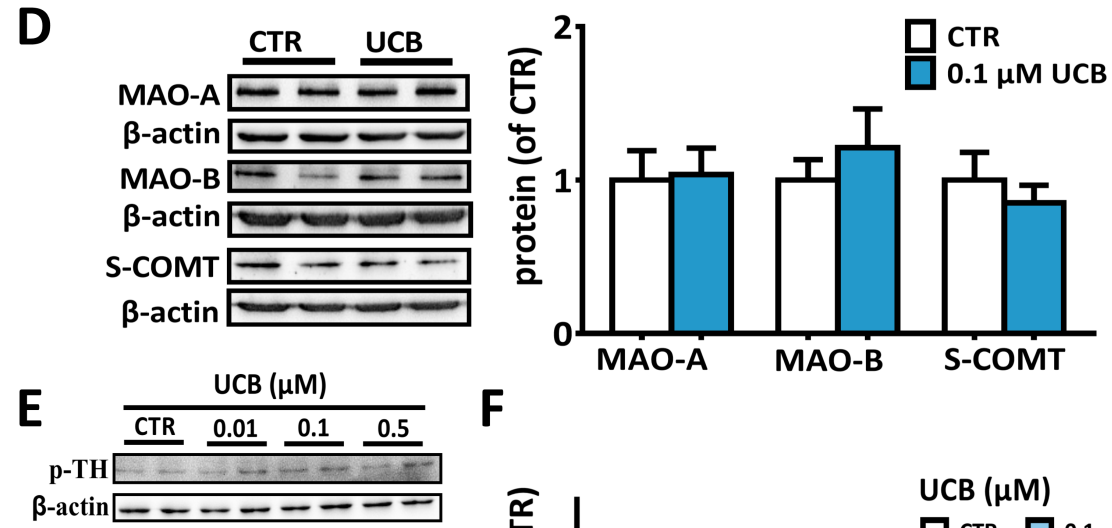

$F$
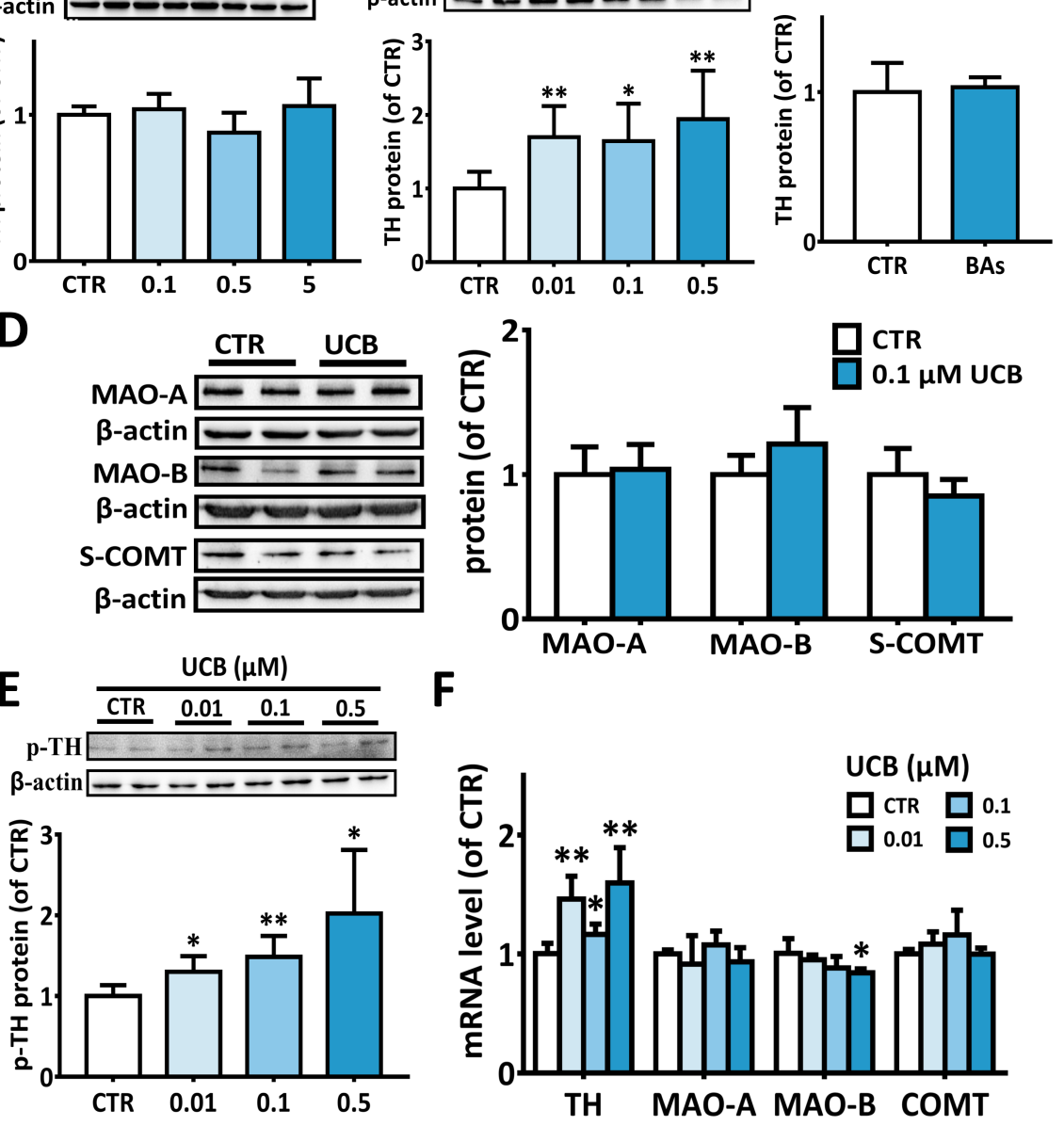

Figure 5 


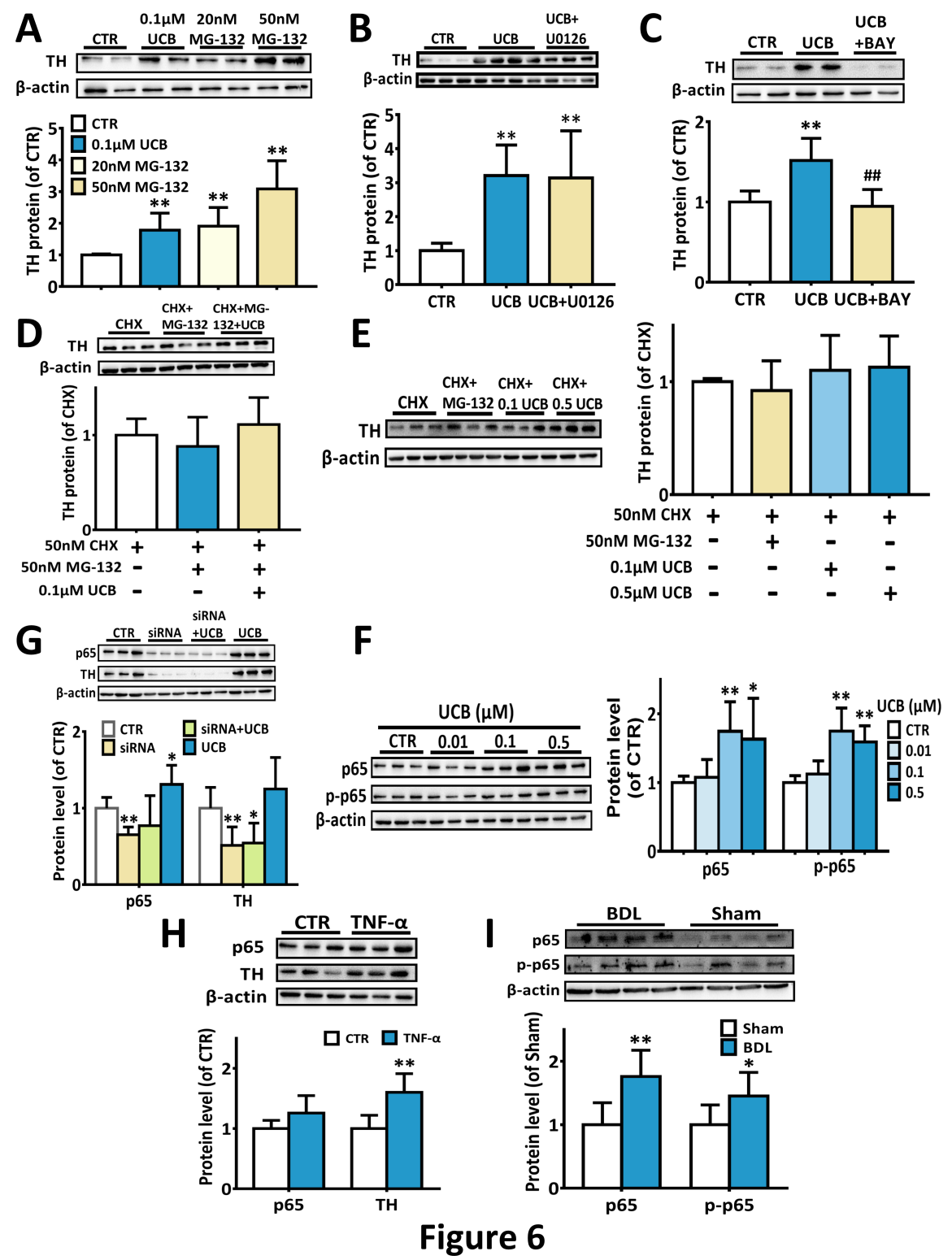




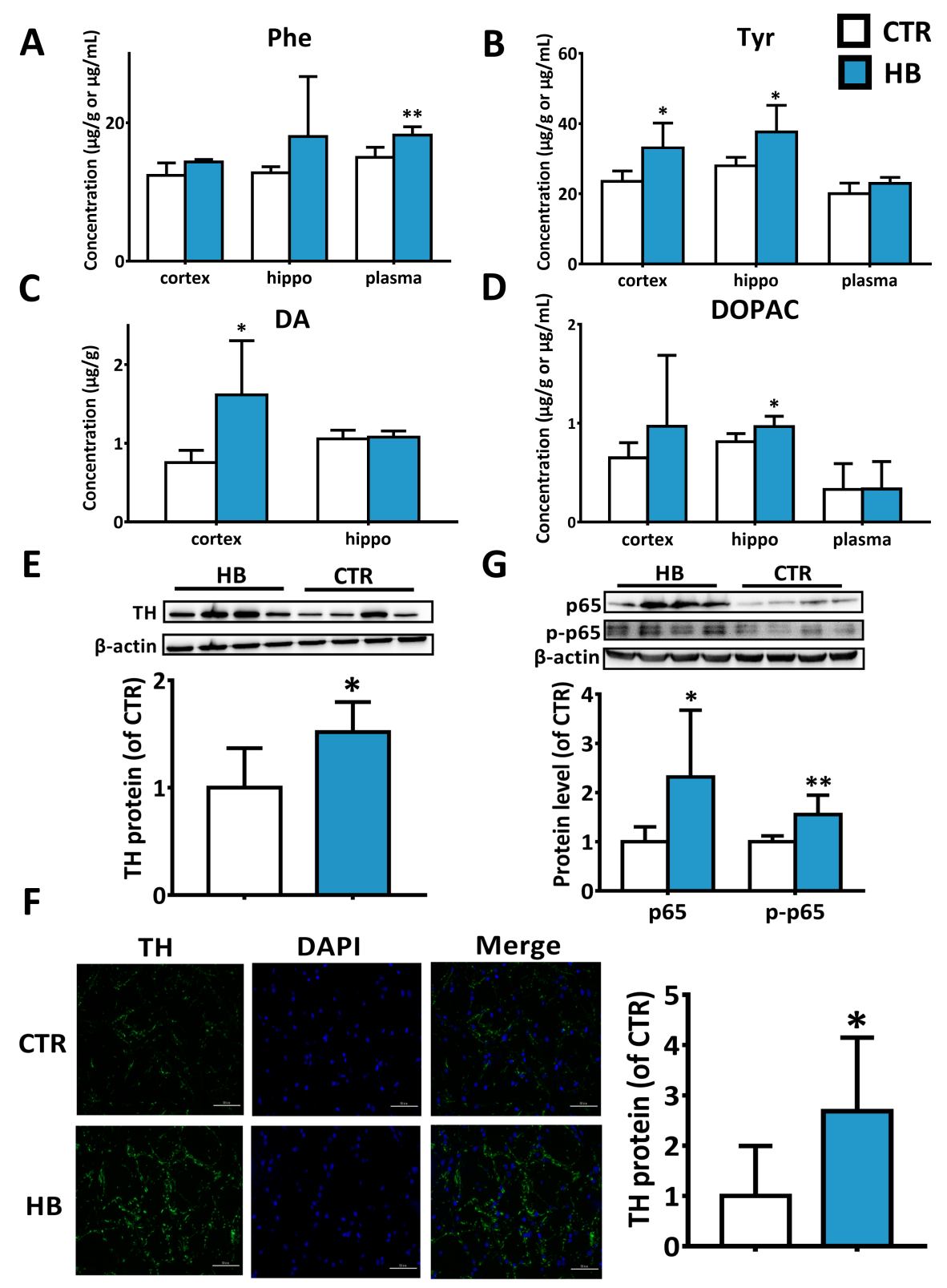

Figure 7 